\title{
3 Research Square \\ Cost-Utility Analysis of Percutaneous and Surgery Methods in Extraction of Cardiac Leads Infection
}

zinab shaker ( $\nabla$ zinab.zohreh@gmail.com )

Kerman University of Medical Sciences https://orcid.org/0000-0002-0364-0033

Mohsen Barooni

Kerman University of Medical Sciences

Asma Saber Mahani

Kerman University of Medical Sciences

Zohreh Shaker

Shiraz University of Medical Sciences

Research

Keywords: Cost-utility analysis, Percutaneous, Surgery, Lead infection, QALY

Posted Date: August 30th, 2021

DOl: https://doi.org/10.21203/rs.3.rs-809065/v1

License: (c) (1) This work is licensed under a Creative Commons Attribution 4.0 International License.

Read Full License 


\section{Abstract}

Introduction: Cardiovascular diseases are currently major concern in the world and It is expected that Until 2030, 7 out of 10 deaths in world will be related to cardiovascular diseases. Despite the increase in Pasemaker and ICD implants in recent years, the complications of this devices are increasing. One of the most important complications is the pulsating lead infection. The purpose of this study was to analyze the cost-effectiveness of percutaneous and surgical method in extracting pacemaker leads with Qaly index.

Methods: In this cross-sectional article (descriptive-analytical) using the Markov model, for compare the two methods of percutaneous and surgery for infectious lead. Sampling was census and (sample size for percutaneous included 57 people) and information about utility was extracted by the SAQ questionnaire. A systematic review was performed to calculate utility of the surgical Cost from the perspective of the service provider. data analysis by SPSS software, and TreeAge software was used for Markov modeland and sensitivity analysis .

Results: Changes in quality of life score in both intervention were incremental and significant and intervention is the only effective factor in changes in quality of life score $(P<0.05)$. The ICER was $5470.44 \$$.

Conclusion: The results of the study show that utility and cost of surgery are higher than the percutaneous method.Sensitivity analysis shows If the cost of surgery increases more than $806.52 \$$ (discount rate of 0.06 ), the percutaneous method dominates the surgery method.

\section{Introduction :}

According to statistics and costs of heart disease, especially in low-medium income countries, the low number of specialists, lack of financial resources is the reason: limit the prevention and management of cardiovascular disease in these countries, and if not considered The incidence of heart disease will increase (1).

One of the heart disease is dysfunction electrical stimulation of heart, which is called arrhythmia (2). Cardiac arrhythmia is due to a defect in the sinus node or atrioventricular node. (3)

It can be controlled with an electronic implantable Cardioverter Defibrillator (ICD) and pacemakers. Pacemakers regulate heart rate and increase life expectancy, improving patients' quality of life. The planting of these devices has increased in recent years (4) .

There are methods for implanting and harvesting pacemaker, For example : Open surgery ) by opening the chest, the electrode is sutured to the Left ventricular epicardium)(5). another method is The percutaneous method ) the genotype is implanted in the subcutaneous tissue of the shelf and lead is guided into subclavian vessels) (6) . 
ICD and pasmaker can cause infection, and studies show that the pasemakes infection changed from $1.5-2.4 \%$ (7). Therefore, with the increase pacemakers, the infection of this device has increased, These infections cause complications and costs, and the cost of treatment of this infection has increased in recent years(8) Infection pacemakers can cause death (9).

Types of complications due to implantation and having pacemakers, including: sepsis and endocarditis infection and pocket infection and other complications such as: drug reaction, bleeding or damage to the arteries and walls of the heart and other organs (10-12).

The lead is parts of the pacemaker that delivers the electrical pulse from the battery to the heart. Lead can cause infection, block arteries, and even death. In severe cases, requires the extraction of leads and the removal of the device and the use of antibiotics (about two-thirds of patients are not treated with antibiotics alone. antibiotics are supplement removal of the device). Leaving leads have complications such as ruptured vessels and perforation of the heart $(9,13)$.

Choosing the right treatment method to prevent recurrence is important because re-treated and Return to the hospital are undesirable Outcome that reduces quality of life in short-term and increased costs(14) .The purpose of this study is cost-utility analysis of percutaneous and surgery methods in extraction of cardiac leads infection .

\section{Method :}

This is cross-sectional article (descriptive-analytical) using the Qaly indexin 2020-2021. In the study, the target group included all patients with infection lead . statistical population included all patients in Kerman that had extracted surgery or percutaneous method. sample size was including 57 patients of percutaneous and Patients' Qaly was calculatedwith questionnaire SAQ. The sample size for the surgical method was limited, Therefore we did systematic review To calculate the Qaly of the surgical method . Hospital records were used to calculate the costs of methods.

\section{Effect}

\section{Effect percutaneous method :}

utility of the percutaneous method was Calculated by the Seattle Angina Questionnaire (SAQ). At first, the questionnaires were given to the patients in two stages before Interventionand 6 months after the intervention. (Consent was obtained from patients to participate in this study).

\section{Effect surgery method:}

To calculate the utility of the surgical method, we had to do a systematic review (due to the limited number of surgical cases). search with the help of experts in databases including : Google scholar Pubmed, Scopu . studies were available until 2021 April 9th day. The search in MESH was done to find synonymous words and the search strategy was written and the search was done. search was performed 
and the results were recorded. Inclusion criteria for randomized clinical trial articles in English and Persian that compare the clinical effect of percutaneous and surgical methods. The results were transferred to Endnote X7 software, then duplicate articles were removed . Then the title, abstract and full text were read (separately by two people) and Exclusion criteria included observational studies, review studies, economic evaluation studies, and unrelated articles. Finally, selected studies were evaluated by Jadad score, which is a score between zero and five, and Studies were accepted with a score above 3; Then, the effect information in the surgical method was extracted and meta-analysis was performed on homogeneous articles.

\section{Transfer probability table :}

The utility weightsand possibility of transition situations was extracted from the studies.

Tablel: Utility weights

\begin{tabular}{|c|c|c|c|}
\hline reference & $\begin{array}{r}\text { utility } \\
\text { weights }\end{array}$ & situations & strategy \\
\hline (109) & 9.80 & well & \multirow[b]{3}{*}{ surgery } \\
\hline (110) & 9.00 & Break the lead & \\
\hline (110) & 9.09 & Re-infection & \\
\hline (104) & 9.52 & well & \multirow{3}{*}{ percutaneous } \\
\hline$(110)$ & 9.00 & Break the lead & \\
\hline (110) & 9.11 & Re-infection & \\
\hline
\end{tabular}

Table2:possibility of transition situation

\begin{tabular}{|c|c|c|c|}
\hline reference: & $\begin{array}{l}\text { possibility of } \\
\text { transition }\end{array}$ & $\begin{array}{l}\text { Transition from state } \mathrm{x} \\
\text { to state } \mathrm{y}\end{array}$ & strategy \\
\hline (103) & 0.91 & well & \multirow{7}{*}{ surgery } \\
\hline$(104,103)$ & 0.97 & Stay to well & \\
\hline$(105)$ & 0.01 & Well to re-infection & \\
\hline$(105)$ & 0.01 & Well to break & \\
\hline$(10)$ & 0.348 & Infection to well & \\
\hline$(104,103)$ & 0.937 & Break to well & \\
\hline$(105)$ & 0.054 & die & \\
\hline (103) & 0.89 & well & \multirow{7}{*}{ percutaneous } \\
\hline (103) & 0.96 & Stay to well & \\
\hline$(106)$ & 0.01 & Well to re-infection & \\
\hline$(105)$ & 0.01 & Well to break & \\
\hline (107) & 0.0182 & Infection to well & \\
\hline (108) & 0.93 & Break to well & \\
\hline$(105)$ & 0.05 & die & \\
\hline
\end{tabular}

\section{Costs:}

The costs were calculated from the perspective of the service provider.Costs were extracted from patients' records. The average total cost wasCalculated (Discount rate of $6 \%$ was considered).(15)

\section{Economic modeling:}

The model presented in this study was the Markov model, which was designed based on the opinions of professors(16) 4 conditions were defined for pations in both methods (well, re-infection, break the lead and injury to heart, die). As can be seen in the Markov model and the decision tree below, people who suffer from complications Three health conditionsin the Markov model. Some of them recovered, some of them became infected again, and some of them died. (The cycle length was considered one year in this study).

\section{data analysis method:}


The utility and cost data were analyzed in SPSS software using TreeAge software version 2020, used to draw the Markov model and Easyfit software was used to determine the data distribution. Incremental cost-effectiveness (ICER) with a threshold of willingness to pay three times the per capita GDP (according to Gaziano's study and WHO proposal, three times the gross national income can be used as a threshold). Iran's per capita GDP in 2018 was $5550.06 \$$ (17), so three times this amount is 16650.18 \$. (In this study, cost discount rate was $6 \%$ and effect discount rate was $3 \%(15,18)$. Finally, two-way and PSA sensitivity analysis was used to evaluate the results $(18,15)$.

\section{Results:}

\section{Results:}

57 patients participated in our study ( 3 patients refused to participate in our study)and 14 studies were found for the surgical method and effect was calculated for Both methods. From the total number of patients surgical method, $74.47 \%$ were male ( 425 patients) and $25.86 \%$ were female ( 145 patients) and From all patients percutaneousmethod, $57.89 \%$ were male ( 33 patients) $(42.10 \%)$ were female (24 patients). mean age of patients percutaneouswas 61.52 with a standard deviation of 13.47 and mean age of patients percutaneouswas 64.19 with a standard deviation of 2.34 . Quality of life Both methods for before and after the intervention (table 3).

\section{Table 3: Quality of life before and after each intervention}

\begin{tabular}{|c|c|c|c|c|c|c|}
\hline \multicolumn{3}{|c|}{ Percutaneous(mean \pm SD) } & \multicolumn{3}{c|}{ surgery (mean \pm SD) } & \multirow{2}{*}{$\begin{array}{c}\text { Quality } \\
\text { of life }\end{array}$} \\
\cline { 1 - 5 } statistical test & after & befor & statistical test & after & bef \\
$\mathrm{t}=-2 / 85$ & $67.34 \pm 16.89$ & $48.38 \pm 20.18$ & $\mathrm{t}=8.28$ & $68.79 \pm 21.81$ & $49.02 \pm 22.09$ & \\
\hline
\end{tabular}

The quality of life obtained from the studies for the surgical strategy according to the table above was $19.77 \pm 6.24$ Quality of life obtained percutaneous method from SAQ was $18.95 \pm 4.09$. The difference scores the two methods was significant.

Table 4 shows the significance of the difference in quality of life obtained from the two interventions .

Table 4: Relationship between intervention and quality of life score changes

\begin{tabular}{|l|c|c|l|l|}
\hline statistical test & Median(IQR) & Average score changes (SD) & \multicolumn{2}{|c|}{ Variable } \\
\hline $\mathrm{Z}=-3 / 13$ & $(10.51) 31.50$ & $(6.24) 19.77$ & surgery & \multirow{2}{*}{ Intervention } \\
\cline { 2 - 4 } $\mathrm{P}=0 / 00$ & $(23.32) 18.00$ & $(4.67) 18.54$ & Percutaneous & \\
\hline
\end{tabular}

$\mathrm{SD}=$ Standard deviation 
Demographic variable had no effect on patients' quality of life two strategies $(P<0.05)$, so demographic variables are not confounding factor.

Table 5 show the direct cost from the perspective of the service provider for both interventions. The mean length of hospital stay patients of surgery was $8.05 \pm 5.43$ days.and for patients of percutaneous was

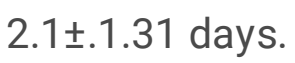

Costs of Prosthesis and Operating room consumables had the largest share in the surgical method, which (32.9 and $28.13 \%$ ), largest share related to the cost of Operating room consumables in the percutaneous method( $32.38 \%)$. The mean total costs of the surgical method is $5135.40 \$$ and The mean total costs of the percutaneous method is $3429.19 \$$.

Table 5: Costs percutaneous and surgical (\$) 


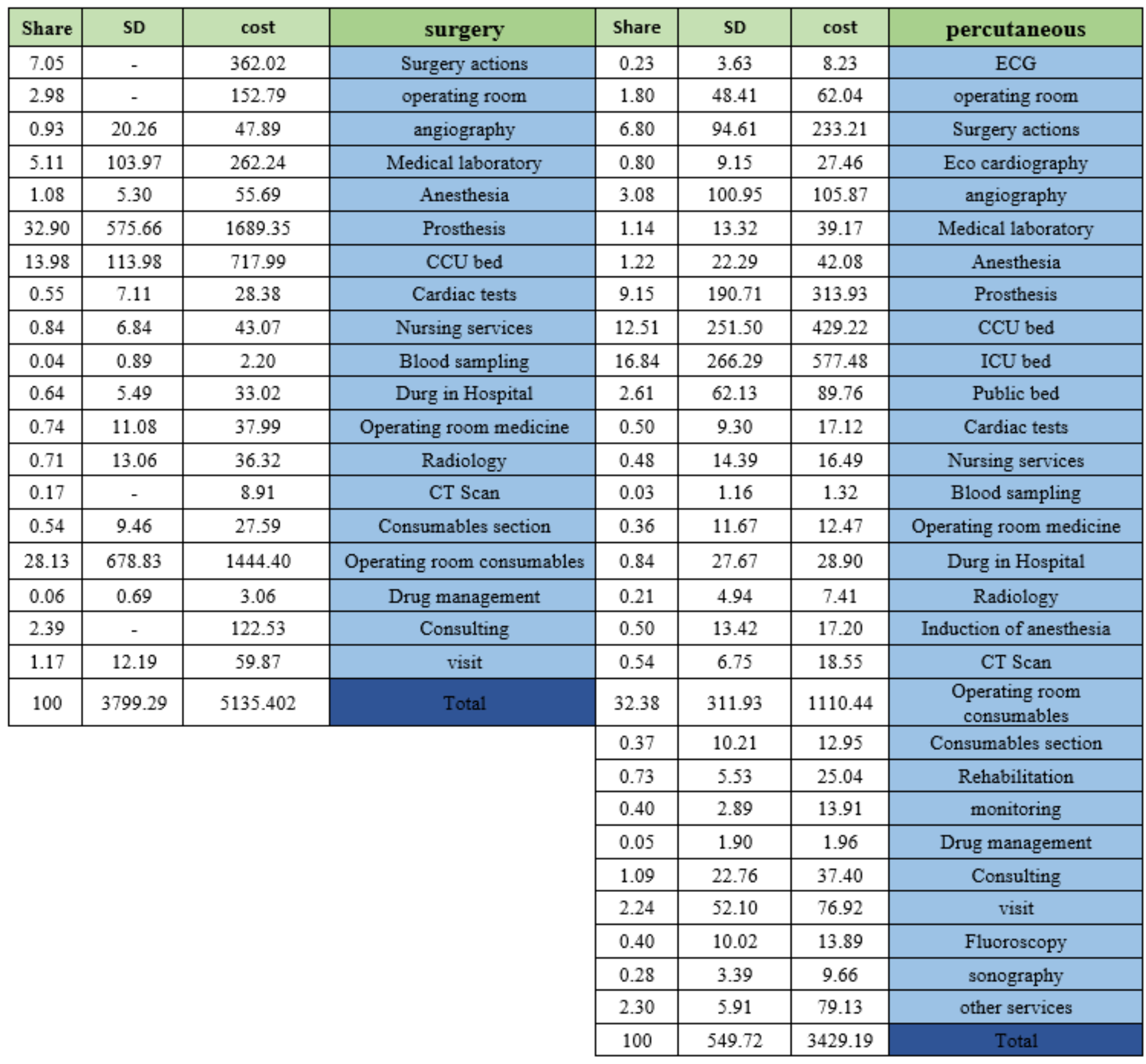

Table 6 show that the utility obtained from the surgical method is higher than the percutaneous method and the cost of the surgical method was higher than the percutaneous method. The Incremental utility was 2.35 Qaly and the Incremental cost was 5470.44ロ\$.The ICER was 5470.44\$.

Table 6: Cost-utility ratio of percutaneous and surgical interventions

\begin{tabular}{|c|c|c|c|c|c|c|c|}
\hline NMB & $\begin{array}{c}\mathrm{C} / \mathrm{E} \\
\text { (ACER) }\end{array}$ & $\begin{array}{c}\text { Incr C/E } \\
\text { (ICER) }\end{array}$ & Incr Cost & Cost & Incr eff & Eff & Strategy \\
\hline 63894779182.00 & 382.83 & - & - & 35450.29 & - & 92.60 & percutaneous \\
\hline 65516134140.43 & 508.73 & 5470.44 & 12854.49 & 48304.78 & 2.35 & 94.95 & surgical \\
\hline
\end{tabular}




\section{sensitivity analysis}

\section{Possible sensitivity analysis:}

Tree-age software was used for sensitivity analysis.. For performed (with $10 \%$ variation rangein parameters) Figure 5 shows the results of probabilistic sensitivity analysis in the cost-effectiveness acceptance curve.

As shown in the figure above, the probability of cost effectiveness of the percutaneous strategy at the willingness to pay threshold is $46 \%$, indicating that the percutaneous strategy at the threshold was nondominant and non-cost effective. In other words, in this threshold, the probability of cost effectiveness of the percutaneous strategy is $0.465 \%$ and the probability of the effectiveness of the surgical method in the threshold is equal to $0.535 \%$.

Figure 6 is the Monte Carlo diagram, which shows the probability of being effective the surgical strategy with threshold of 16650.18 \$.

The Incremental cost effectiveness diagram shows, about $46 \%$ of the points on the left and $53 \%$ of the points on the right, which shows the probability of dominance of the surgical strategy is $53 \%$ (Figure 7 )

\section{two-way sensitivity analysis:}

Figure 8 is a two-way sensitivity analysis of the two variables of the discount rate and the cost of the surgical method.

The results of two-way sensitivity analysis with two variables of surgical cost and discount rate showed that if the discount rate changes from 0.01 to 0.1 and also the cost of surgery from 2333.33 to $16666.66 \$$, Shows that the model is sensitive to the simultaneous change of two variables, so that in the discount rate of 0.06 , Sensitivity analysis shows If the cost of surgery increasesmore than $806.52 \$$ (discount rate of 0.06 ), the percutaneous method dominates the surgerymethod. (Figure 8 ).

\section{Discussion:}

Study by Ahmed et al. (2019) Between 2013 and 2015, 106 patients To suffer infection. The average extraction cost was 1729.95 Pound. The cost of the hospital stay is reported 3,150 Pound. The length of hospital stay was reported to be between 5 and 18 days (19).

Menezes Junior et al. (2018) from 2009 to 2016 with a systematic review In this study, out of 3354 patients, 3081 successfully extracted lead and the success rate was reported by percutaneous method $92.4 \%$. The incidence of severe complications was $2.9 \%$ and the incidence of mild complications was $8.4 \%$ and the mortality rate in hospital was $5.4 \%$ and the mortality from this method was 0.4 to $3.6 \%$. The average mortality after 6 months was $20 \%$ and after one year follow-up was $14 \%$ (20). 
Soheil et al. (2011), there were 5817 reception with infection, the rate of reception adjusted with mortality ranged from 4.6 to $11.3 \%$ and the duration of hospitalization with infection was between 15.5 to $24.3 \%$. Depending on the device type, the total costs of Patient reception with infection from 15 treatment centers ranged from $14,360 \$$ to $16,498 \$$ and $28,676 \$$ to $53,349 \$$, respectively. The findings showed that the mortality rate and cost ratio in pacemakers were significantly higher than implantable ICD (21)

John M. Kratz et al (2010) Expressed that the need for lead extraction was increasing. Removing the device can be dangerous, difficult or unsuccessful. In the present study, the results and techniques that have been used in 365 patients since 1992 were reviewed. The results showed that out of 365 patients who underwent surgery, 235 were due to infectious lead and 130 were removed due to non-infectious lead extraction. With laser extraction $93 \%$ the bleeding rate was $1.9 \%$ and there was no mortality due to removal of the device. All deaths were befor surgery and due to Septicemia. The method of surgery and the experienced team were effective in the success of the operation and more than $90 \%$ of patients had low complications and no deaths(22).

Peter Nozil et al.)2007) with title " Pacemaker and ICD lead extraction with electrosurgical dissection sheaths and standard transvenous extraction systems" Over 10 years, 462 patients underwent percutaneous lead extraction with a mean age 6/9 $\pm 7 / 62$ years. The mean time from implanting until extraction was $73.4 \pm 15.7$ months. The most common reason for lead extraction was infection (95.6\%). The results showed that $93 \%$ of the leads were successfully extracted (23).

Valiollah Khedir (2009) with title "Pacemaker implantation by surgeons and cardiologists: A comparison of two different periods" 114 patients were implanted by surgery and 299 patients by percutaneous in Shahid Rajaei Hospital. reviewing the hospital file information and questionnaire in the first group and collecting information related to the method of implantation Complications. The results showed that implantation of pacemaker by percutaneous method did not have more complications than surgical method. Also, the mean hospital stay in patients who underwent surgery and percutaneous method was $7.4 \pm 10.2$ and $6.9 \pm 7.8$ days, respectively(24)).

\section{Conclusion:}

The findings of the present study showed that the surgical strategy for treating patients with lead pacemaker and ICD infection is more cost effective than the percutaneous method. Although the surgical strategy is more effective than the percutaneous strategy, the results of sensitivity analysis showed that if the surgery costs is more than $809.52 \$$, with a discount rate of 0.06 , the percutaneous strategy will be effective.

\section{Declarations}

Ethical confirmation and consent were obtained to participate in the study.

Ethical approval by the hospital and The university approved the study 
Acknowledgements

Thanks to the staff of Shafa Hospital for collecting data

Thanks to the cooperation of Kerman University of Medical Sciences

\section{Authors' contributions}

Thanks to Dr. Mohsen Baroni for valuable tips and thanks to Dr. Asma Saber Mahani for good advice and thanks to Zohreh Shaker for collaborating in writing this manuscript.

All authors read and approved the final manuscript.

\section{Funding}

This study was not funded by any source.

\section{Availability of data and materials}

The data and material that support the findings of this study are available

\section{Code availability}

The study was performed by software package Tree-Age pro 2020. The Tree Age Pro Trex files are available from the corresponding author on reasonable request.

\section{Consent for publication}

No assistance in the preparation of this article is to be declared.

\section{Competing interests}

The authors have no conflicts of interest to declare.

\section{References}

1. Arena R. Lifestyle modification interventions and cardiovascular health: global perspectives on worksite health and wellness and cardiac rehabilitation. Progress in cardiovascular diseases. 2013;56(5):473-5.

2. Angelone A, Coulter JR NA. Respiratory sinus arrhythmia: a frequency dependent phenomenon. Journal of Applied Physiology. 1964;19(3):479-82.

3. español Le. Arrhythmia. . national heart lung and blood institute. 2011(https://www.nhlbi.nih.gov/health-topics/arrhythmia). 
4. Mikulic M. Global number of pacemakers in 2016 and a forecast for 2023. 2017:https://www.statista.com/statistics/800794/pacemakers-market-volume-in-units-worldwide/. .

5. thoracickey. Pacemakers. 2016:https://thoracickey.com/pacemakers/.

6. Stähli BE, Nietlispach F, Meier B. Percutaneous PFO Closure: History, Devices, Techniques, Safety, and Informed Consent. Patent Foramen Ovale Closure for Stroke, Myocardial Infarction, Peripheral Embolism, Migraine, and Hypoxemia: Elsevier; 2020. p. 171-84.

7. Easo J, Book M, Hakmi S, Weymann A. Misplaced Ventricular Lead via an Atrial Septal DefectPercutaneous Extraction. The Thoracic and cardiovascular surgeon reports. 2019;8(1):e8.

8. Tofighi S, Ahmad Kiadaliri A, Sadeghifar J, Raadabadi M, Mamikhani J. Health-related quality of life among patients with coronary artery disease: a post-treatment follow-up study in Iran. Cardiology research and practice. 2012;2012.

9. de Alarcón A. Infections on Cardiovascular Implantable Electronic Devices: a critical review. Medical Research Archives. 2019;7(3).

10. Kawata H, Pretorius V, Phan H, Mulpuru S, Gadiyaram V, Patel J, et al. Utility and safety of temporary pacing using active fixation leads and externalized re-usable permanent pacemakers after lead extraction. Europace. 2013;15(9):1287-91.

11. Kennergren C, Bucknall C, Butter C, Charles R, Fuhrer J, Grosfeld M, et al. Laser-assisted lead extraction: the European experience. Europace. 2007;9(8):651-6.

12. Paraskevaidis S, Konstantinou D, Vassilikos V, Theofilogiannakos E, Mantziari L, Megarisiotou A, et al. Percutaneous extraction of transvenous permanent pacemaker/defibrillator leads. BioMed research international. 2014;2014.

13. Bracke F. Complications and lead extraction in cardiac pacing and defibrillation. Netherlands Heart Journal. 2008;16(1):27-30.

14. Vieira RDO, Hueb W, Hlatky M, Favarato D, Rezende PC, Garzillo CL, et al. Cost-effectiveness analysis for surgical, angioplasty, or medical therapeutics for coronary artery disease: 5-year follow-up of medicine, angioplasty, or surgery study (MASS) II trial. Circulation. 2012;126(11_suppl_1):S145-S50.

15. Mahboub-Ahari A PA, Sari AA, Rahimi Foroushani A, Heydari H. . Stated time preferences for health: a systematic review and meta analysis of private and social discount rates. Journal of research in health sciences; . . 2014;14(3):181-6.

16. Atehortúa S SJ, Castro P, Ceballos M, Saldarriaga C, Giraldo N, et al. . Cost-utility analysis of an implantable cardioverterdefibrillator for the treatment of patients with ischemic or non-ischemic New York Heart Association class II or III heart failure in Colombia. Biomédica. ;. 2019:39:502-12. . 
17. World Bank. GDP per capita 2019 [Available from: https://data.worldbank.org/indicator/NY.GDP.PCAP.CD.

18. Mahboub-Ahari A, Pourreza A, Sari AA, Rahimi Foroushani A, Heydari H. Stated time preferences for health: a systematic review and meta analysis of private and social discount rates. Journal of research in health sciences. 2014;14(3):181-6.

19. Ahmed FZ FC, Zaman M, Qamruddin A, Cunnington C, Mamas MA, et al. . Cardiac implantable electronic device (CIED) infections are expensive and associated with prolonged hospitalisation: UK Retrospective Observational Study. PloS one. 2019; ;14.

20. Menezes Junior ADS MT, Morais AOA. Percutaneous Lead Extraction in Infection of Cardiac Implantable Electronic Devices: a Systematic Review. Braz J Cardiovasc Surg. 2018;;33(2):194-202.

21. Sohail MR HC, Braid-Forbes MJ, Forbes KF, Lerner DJ.

. Mortality and cost associated with cardiovascular implantable electronic device infections. Arch Intern Med. . 2011.

22. Kratz JM, Toole JM. Pacemaker and internal cardioverter defibrillator lead extraction: a safe and effective surgical approach. The Annals of thoracic surgery. 2010;90(5):1411-7.

23. Neuzil P, Taborsky M, Rezek Z, Vopalka R, Sediva L, Niederle P, et al. Pacemaker and ICD lead extraction with electrosurgical dissection sheaths and standard transvenous extraction systems: results of a randomized trial. Europace. 2007;9(2):98-104.

24. Dr. Valiollah Khadir 1 DSO. Pacemaker implantation by surgeons and cardiologists: A comparison of two different periods. 2020:12.4: 9-24.

25. Zhang Z, Mahoney EM, Stables RH, Booth J, Nugara F, Spertus JA, et al. Disease-specific health status after stent-assisted percutaneous coronary intervention and coronary artery bypass surgery: one-year results from the Stent or Surgery trial. Circulation. 2003;108(14):1694-700.

26. Sands BE, Arsenault JE, Rosen MJ, Alsahli M, Bailen L, Banks P, et al. Risk of early surgery for Crohn's disease: implications for early treatment strategies. The American journal of gastroenterology. 2003;98(12):2712-8.

27. Borkon AM, Muehlebach GF, House J, Marso SP, Spertus JA. A comparison of the recovery of health status after percutaneous coronary intervention and coronary artery bypass. The Annals of thoracic surgery. 2002;74(5):1526-30.

28. Zhang Z, Mahoney EM, Spertus JA, Booth J, Nugara F, Kolm P, et al. The impact of age on outcomes after coronary artery bypass surgery versus stent-assisted percutaneous coronary intervention: one-year results from the Stent or Surgery (SoS) trial. American heart journal. 2006;152(6):1153-60. 
29. Zhang Z, Weintraub WS, Mahoney EM, Spertus JA, Booth J, Nugara F, et al. Relative benefit of coronary artery bypass grafting versus stent-assisted percutaneous coronary intervention for angina pectoris and multivessel coronary disease in women versus men (one-year results from the Stent or Surgery trial). The American journal of cardiology. 2004;93(4):404-9.

30. McGrath BM. Quality of Life (QOL) in Diabetics with Multi-Vessel Coronary Artery Disease: Real-World Experience Comparing Percutaneous Coronary Intervention (PCl) and Coronary Artery Bypass Grafting (CABG). 2015.

31. Fakhrzad N, Goudarzi R, Barouni M, Kojuri J, Jahani Y. Examining the health-related quality of life after coronary artery bypass grafting and percutaneous coronary intervention in Iran via SF-36 and SAQ. Int Cardiovasc Res J. 2016;10:123-8.

32. Abdallah MS, Wang K, Magnuson EA, Spertus JA, Farkouh ME, Fuster V, et al. Quality of life after PCI vs $C A B G$ among patients with diabetes and multivessel coronary artery disease: a randomized clinical trial. Jama. 2013;310(15):1581-90.

33. Baron SJ, Chinnakondepalli K, Magnuson EA, Kandzari DE, Puskas JD, Ben-Yehuda O, et al. Quality-oflife after everolimus-eluting stents or bypass surgery for left-main disease: results from the EXCEL trial. Journal of the American College of Cardiology. 2017;70(25):3113-22.

34. Yang L-X, Zhou Y-J, Wang Z-J, Li Y-P, Chai M. Impact of invasive treatment strategy on health-related quality of life six months after non-ST-elevation acute coronary syndrome. Journal of geriatric cardiology: JGC. 2014;11(3):206.

35. Conaway DG, House J, Bandt K, Hayden L, Borkon AM, Spertus JA. The elderly: health status benefits and recovery of function one year after coronary artery bypass surgery. Journal of the American College of Cardiology. 2003;42(8):1421-6.

36. Bach RG. CABG and PCI did not differ clinically for angina relief in severe CAD. Annals of internal medicine. 2011;155(4):JC1-10.

37. Zhao Y, Meng S, Liu T, Dong R. Economic Analysis of Surgical and Interventional Treatments for Patients with Complex Coronary Artery Disease: Insights from a One-Year Single-Center Study. Medical science monitor: international medical journal of experimental and clinical research. 2020;26:e919374-1.

38. Cohen DJ, Van Hout B, Serruys PW, Mohr FW, Macaya C, Den Heijer P, et al. Quality of life after PCl with drug-eluting stents or coronary-artery bypass surgery. New England Journal of Medicine. 2011;364(11):1016-26.

\section{Figures}




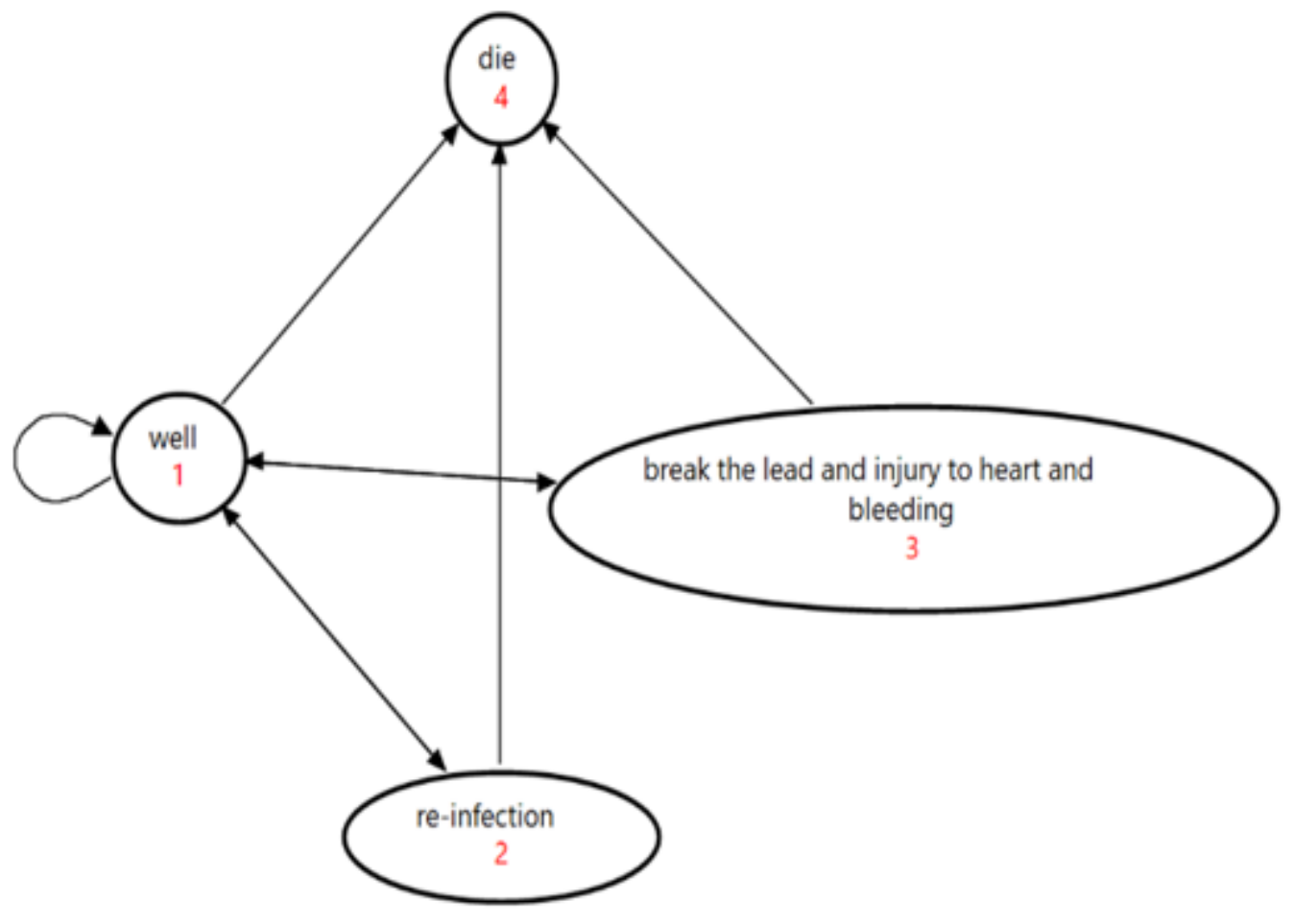

Figure 1

Markov model in surgical method

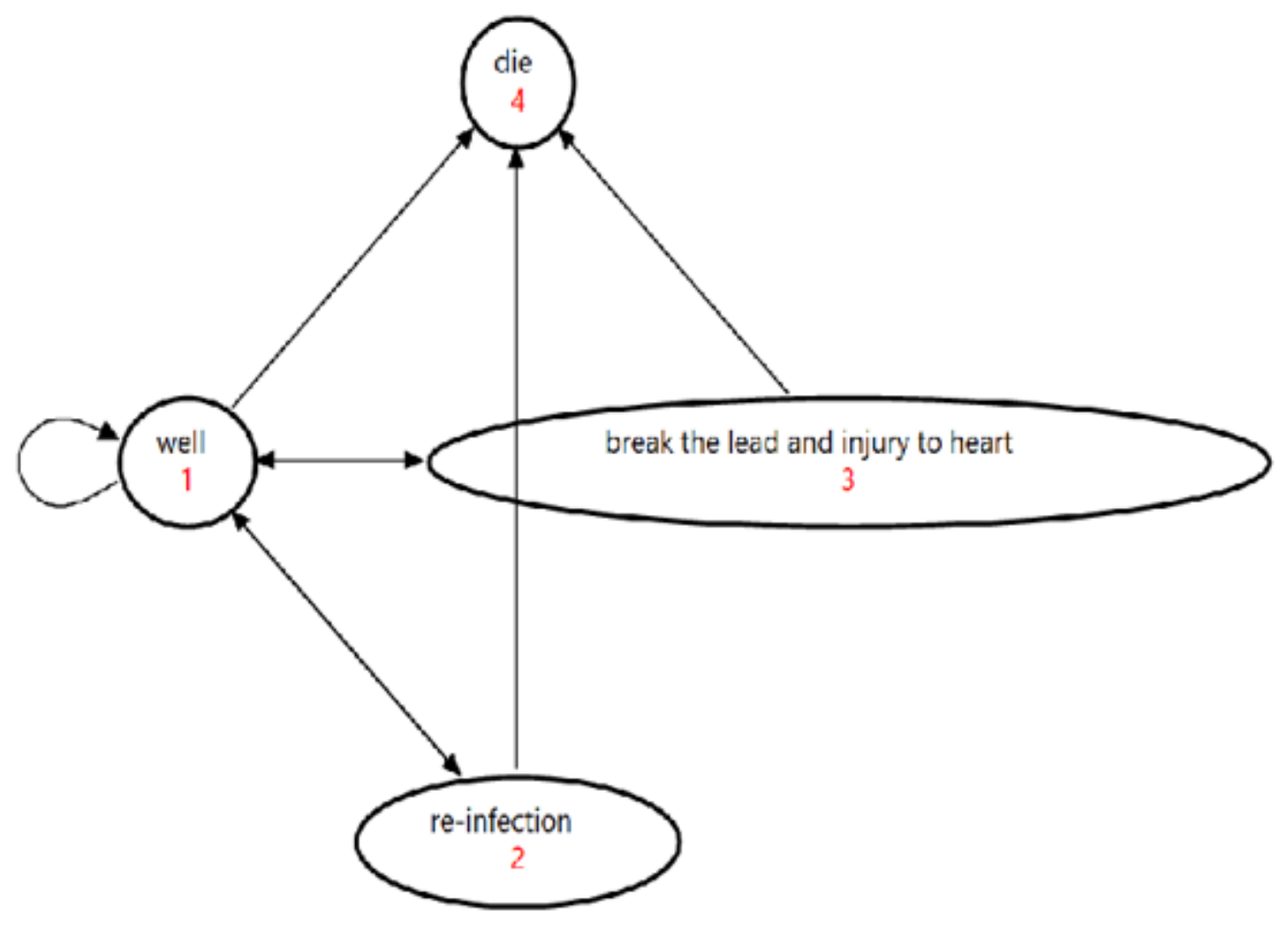


Figure 2

Markov model in percutaneous method

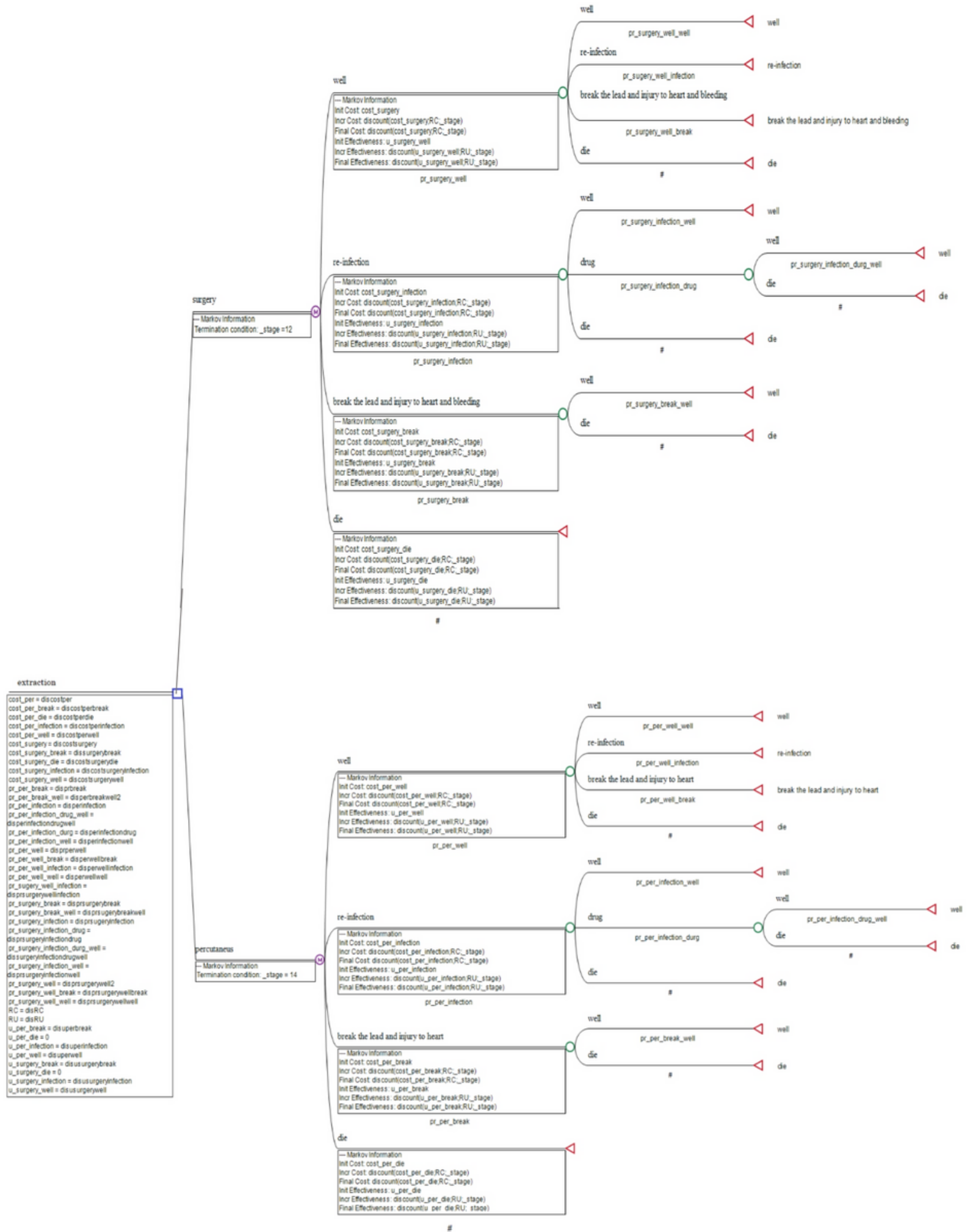

Figure 3

decision tree 


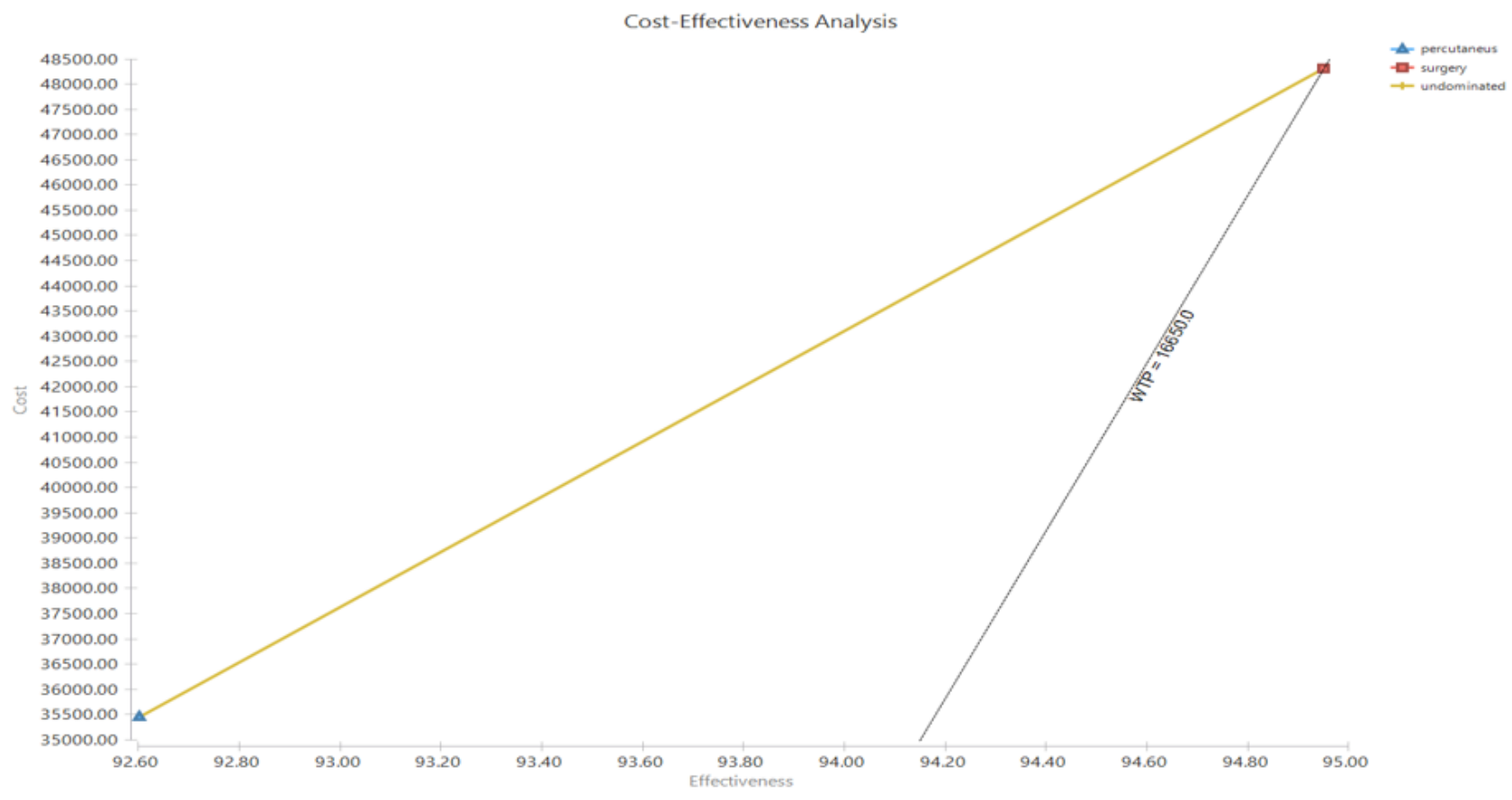

\section{Figure 4}

Cost - utility surgical method and percutaneous method and threshold

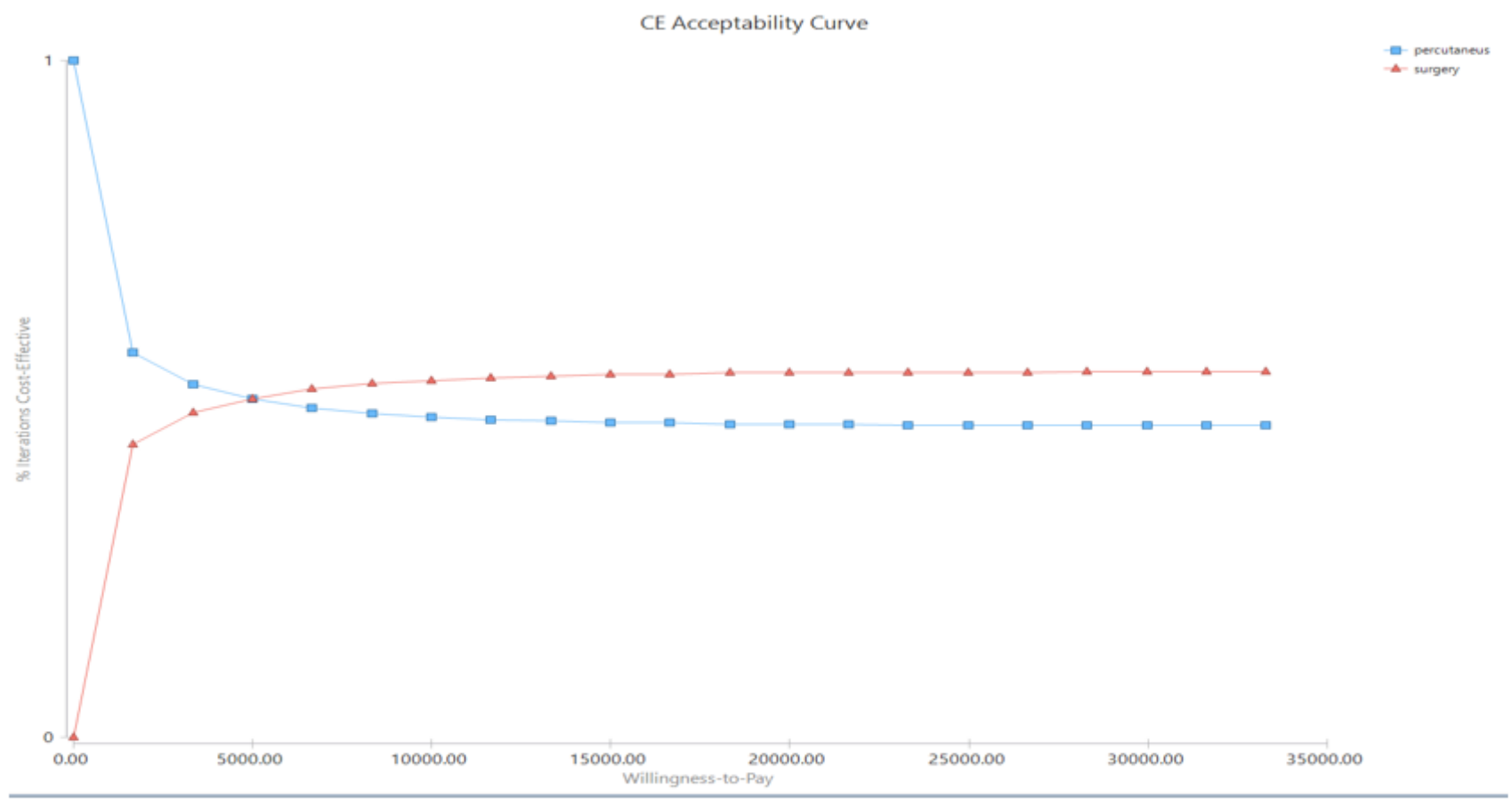

Figure 5

the cost-effectiveness acceptance chart of the chart 
Monte Carlo Acceptability at WTP

(WTP: 16650.0)

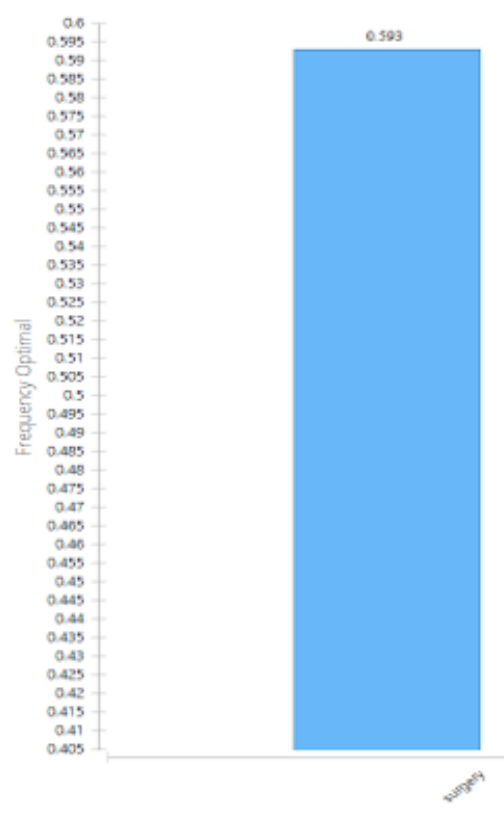

\section{Figure 6}

\section{Monte Carlo Sensitivity Analysis diagram}

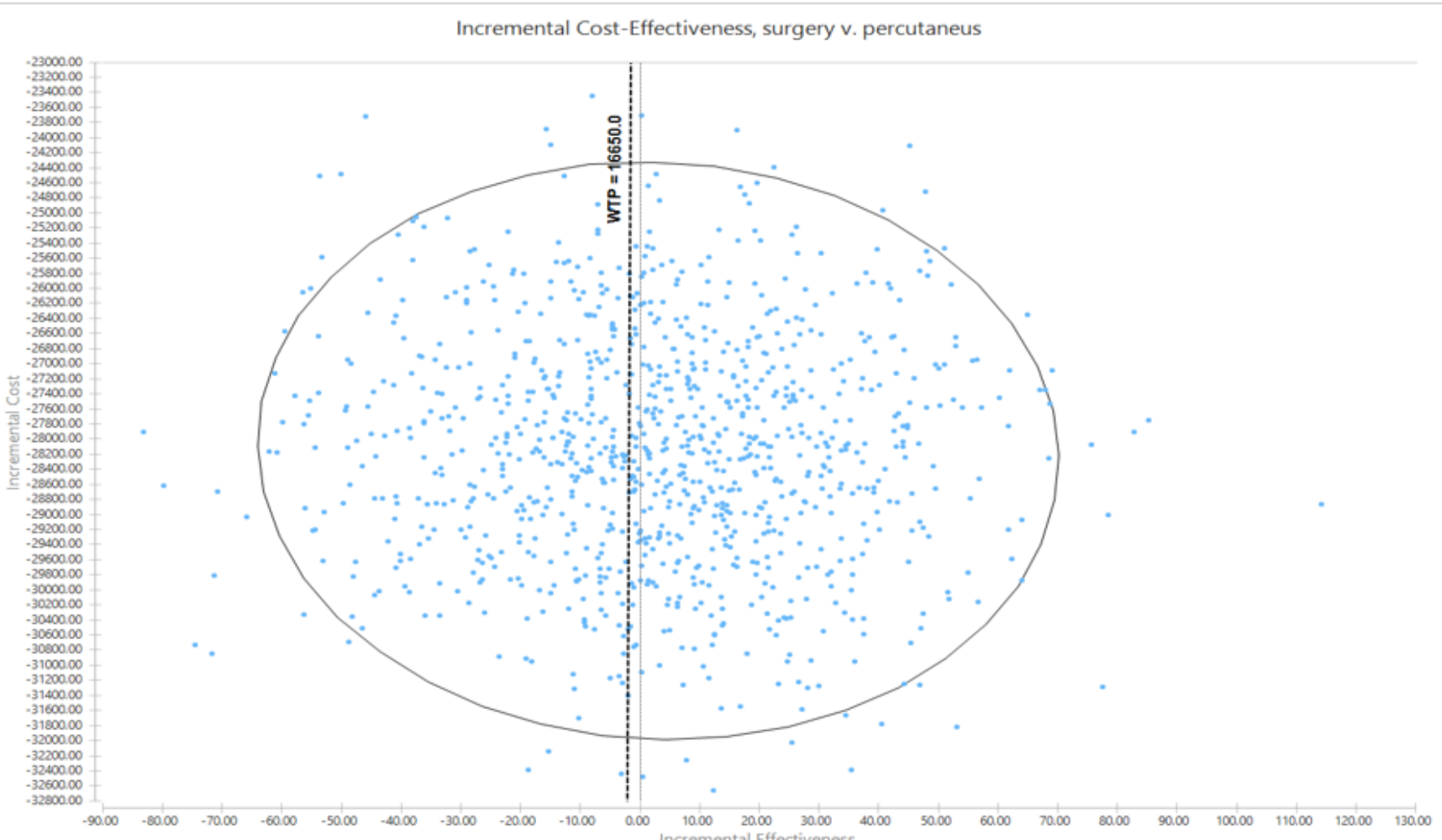

Figure 7 
The Incremental cost effectiveness surgical strategy to percutaneous strategy

Sensitivity Analysis on cost_surgery and RC

(Net Benefit, WTP $=16650.0$ )

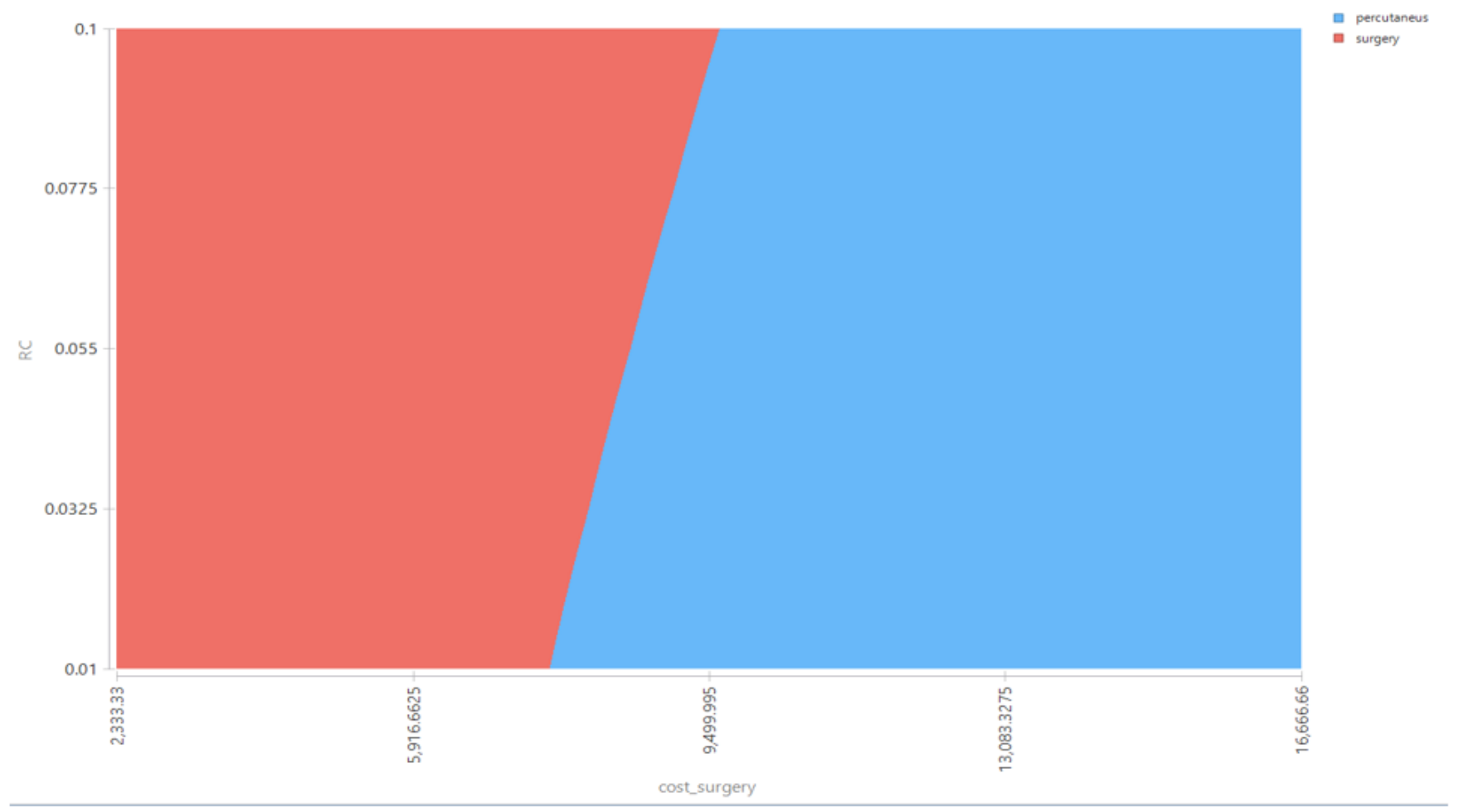

Figure 8

Diagram of two-way sensitivity analysis of surgery cost and cost discount rate

\section{Supplementary Files}

This is a list of supplementary files associated with this preprint. Click to download.

- Attach12.docx 